\title{
Lipoprotein Patterns in Diet, Sulphonylurea, and Insulin Treated Diabetics
}

\author{
H.-J. Lisch and S. Sailer \\ Universitätsklinik für Innere Medizin, Innsbruck, Austria
}

Summary. In order to study the lipoprotein pattern in diabetes mellitus, plasma lipoproteins were isolated by rate zonal centrifugation in 12 control subjects (median fasting blood glucose level: $80 \mathrm{mg} / \mathrm{dl}$ (range: 74-86) ), 14 diabetic patients treated by diet alone $104 \mathrm{mg} / \mathrm{dl}$ (76-153), 27 patients treated by diet plus insulin $(180 \mathrm{mg} / \mathrm{dl}(106-404))$, and 32 patients treated by diet plus sulphonylurea $[178 \mathrm{mg} / \mathrm{dl}$ (103-361)]. No significant differences of median relative body weight existed between the four groups. Neither the diabetic group on diet alone nor the insulin-treated group differed significantly from control subjects with respect to lipid and lipoprotein concentrations. Diabetics treated with diet plus sulphonylurea, however, differed significantly from the control group with regard to the following parameters (median and range); plasma triglycerides (210 $[75-620) \mathrm{mg} / \mathrm{dl} ; \mathrm{p}<0.01)]$ and intermediate density lipoproteins $(65(10-338) \mathrm{mg} / \mathrm{dl} ; \mathrm{p}<0.05))$ were higher; low density lipoproteins $(236(82-418) \mathrm{mg} /$ $\mathrm{dl} ; \mathrm{p}<0.05))$ and high density lipoproteins ${ }_{2}\left(\mathrm{HDL}_{2}\right)$ $[51(12-121) \mathrm{mg} / \mathrm{dl} ; \mathrm{p}<0.01)]$ concentrations were lower. When data from all 85 studied individuals were analysed together, significant positive correlations were observed between fasting blood glucose and plasma triglyceride concentration $(\mathrm{r}=0.28$, $\mathrm{p}<0.01$ ), and between fasting blood glucose and plasma very low density lipoproteins (VLDL) $(\mathrm{r}=$ $0.23, p<0.05$ ). A negative correlation was found between blood glucose and plasma $\mathrm{HDL}_{2}(\mathrm{r}=-0.29$, $\mathrm{p}<0.01$ ). In addition, VLDL correlated negatively with $\mathrm{HDL}_{2}(\mathrm{r}=-0.89, \mathrm{p}<0.001)$ but not with plasma $\mathrm{HDL}_{3}$ concentration. It is concluded that the deranged lipoprotein metabolism in diabetes mellitus may be better controlled by insulin than by sulphonylureas.

Key words: Non-insulin-dependent diabetes, insulin treatment, sulphonylurea treatment, triglycerides, VLDL, IDL, LDL, HDL fractions
Diabetes has been reported to be a major contributor to cardiovascular morbidity [1] and mortality with a twofold to threefold increase of clinical atherosclerosis [2]. The incidence of macroangiopathy does not, however, correlate well with diabetic control, and atherosclerosis in the general population is more closely linked to abnormalities of plasma lipids than to hyperglycaemia. It is well-known that abnormal lipid metabolism often coexists with hyperglycaemia in the diabetic patient. Thus, in most surveys, the incidence of fasting hyperlipoproteinaemia in diabetes is 30 to 40 percent [ 3,4$]$. Most commonly, fasting plasma triglyceride levels are elevated, but cholesterol concentration may also be increased in the diabetic population $[3,4,5,6]$. The absence of fasting hyperlipidaemia does not, however, assure either normal lipid homeostasis or freedom from vascular disease.

Recently, attention has been paid to the relationship of HDL (high density lipoproteins) and diabetes. In contrast to VLDL (very low density lipoproteins) and LDL (low density lipoproteins), HDL have been suggested to protect against atherosclerosis [7, 8]. In most studies, HDL cholesterol was used as a measure of HDL concentration in plasma, in spite of the fact that Gofman et al. [9] demonstrated quite clearly that only the $\mathrm{HDL}_{2}$ fraction is lowered in patients with atherosclerosis.

Many recent studies have dealt with the investigation of HDL plasma concentration in patients with diabetes mellitus [10-15], and significant correlations between control of diabetes and HDL concentration have been reported by some $[10,12,13]$ although not by others $[9,14]$. The interpretation of the results obtained so far has been difficult, because: a) diabetics form a highly heterogeneous group; many other factors such as alcohol intake, body weight, sex, and smoking habits influence the concentrations of plasma HDL; b) HDL consist of at least two different subgroups, $\mathrm{HDL}_{2}$ and $\mathrm{HDL}_{3}$, which differ from each other with regard to their 
Table 1. Clinical and biochemical characteristics of the patients

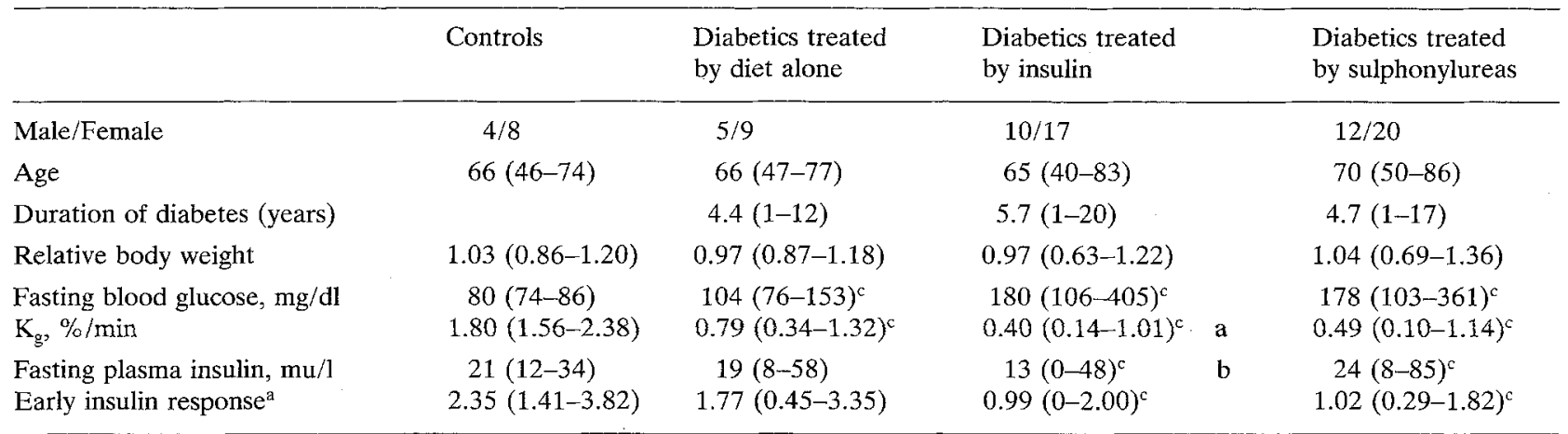

Results are given as median and range

a Plasma insulin, 10 minutes after glucose Fasting plasma insulin

Difference from control group: ${ }^{c} \mathrm{p}<0.01$

Differences between insulin group and sulphonylurea group: a: $p<0.05 ; b$ : $p<0.01$

Table 2. Plasma lipid and lipoprotein concentrations of the patients

\begin{tabular}{|c|c|c|c|c|c|}
\hline $\mathrm{mg} / \mathrm{dl}$ & Controls & $\begin{array}{l}\text { Diabetics treated } \\
\text { with diet alone }\end{array}$ & $\begin{array}{l}\text { Diabetics treated } \\
\text { by insulin }\end{array}$ & & $\begin{array}{l}\text { Diabetics treated } \\
\text { by sulphonylureas }\end{array}$ \\
\hline Cholesterol & $254(183-290)$ & $232(112-325)$ & $247(165-334)$ & & $237(138-380)$ \\
\hline Triglycerides & $122(73-189)$ & $129(64-369)$ & $174(74-880)$ & a & $210(75-620)^{\mathrm{b}}$ \\
\hline Phospholipids & $219(183-252)$ & $206(149-282)$ & $238(137-394)$ & & $234(125-394)$ \\
\hline HDL-cholesterol & $66(41-97)$ & $64(46-89)$ & $62(35-105)$ & $\mathrm{b}$ & $52(26-92)^{b}$ \\
\hline VLDL & $65(23-208)$ & $63(20-407)$ & $103(19-750)$ & & $149(40-407)$ \\
\hline IDL & $27(10-114)$ & $39(15-144)$ & $57(10-273)$ & & $65(10-338)^{a}$ \\
\hline $\mathrm{LDL}$ & $323(210-400)$ & $279(154-410)$ & $267(120-492)$ & & $236(82-418)^{a}$ \\
\hline $\mathrm{HDL}_{2}$ & $89(63-116)$ & $81(37-152)$ & $72(18-232)$ & $b$ & $51(12-121)^{b}$ \\
\hline $\mathrm{HDL}_{3}^{2}$ & $233(186-279)$ & $227(174-528)$ & $206(113-343)$ & & $232(135-380)$ \\
\hline
\end{tabular}

Results are given as median and range

Lipoprotein densities VLDL: $\mathrm{d}<1.006$; $\mathrm{d}<1.006-1.020$; LDL: $\mathrm{d}<1.020-1.063 ; \mathrm{HDL}_{2}: \mathrm{d}<1.063-1.125 ; \mathrm{HDL}_{3}: \mathrm{d}<1.125-1.21 \mathrm{~g} / \mathrm{ml}$ Difference from control group: ${ }^{a} \mathrm{p}<0.05 ;{ }^{b} \mathrm{p}<0.01$

Differences between insulin group and sulphonylurea group: $a: p<0.05 ; b: p<0.01$

plasma concentration, chemical composition, and their metabolic function.

The aim of this study was to investigate the lipoprotein patterns of patients with diabetes mellitus treated by diet alone, as well as with diabetes treated by insulin or sulphonylureas.

\section{Patients and Methods}

Eighty-five individuals were studied (see Table 1 for clinical and biochemical characteristics). Twelve age and sex matched persons with a normal glucose disappearance rate after intravenous glucose $\left(K_{g}>1.5\right)$ served as a control group. These individuals were obtained from the population who had attended the diabetic outpatient clinic for routine exclusion of diabetes mellitus.
The 73 diabetic patients had been seen regularly at our diabetic outpatient clinic for at least the last 3 years. The diet-treated diabetics had been seen at 3 monthly intervals, the insulin-treated patients and the sulphonylurea-treated patients at least every 2 months. Each patient had received the same treatment for at least the last year. The insulin-treated group received a long-acting insulin preparation (Insulin Novo Lente) in a single dose daily in the morning. The average dose in the 27 insulin-treated patients was $40 \mathrm{U} /$ day (range $24-60 \mathrm{U}$ ). On the day of investigation, the patients received no insulin. The sulphonylurea group took either tolbutamide, $1 \mathrm{~g}$ twice daily (16 patients), or glibenclamide, $5 \mathrm{mg}$ twice daily (16 patients). The evening dose was ommitted on the day before the study. All individuals had ceased appreciable nicotine and alcohol consumption for at least 1 year before the investigation. Relative body weight of the individuals was calculated by division of their actual body weight by their average body weight [16]. All patients gave informed consent for the study. 


\section{Methods}

An IV glucose tolerance test was performed at $0800 \mathrm{~h}$ in the recumbent position by rapid injection of glucose $0.33 \mathrm{~g} / \mathrm{kg}$ body weight. The glucose disappearance rate after glucose $\left(K_{\mathrm{g}}\right)$ was calculated from the semi-logarithmic expression of the fall in blood glucose levels. Immediately before the test, approximately $100 \mathrm{ml}$ venous blood were drawn using heparin as an anticoagulant. Plasma concentrations were determined for free and esterified cholesterol using the Cholesterol Enzymatic Color Test (Boehringer Mannheim GmbH) [17, 18], triglycerides [19], phospholipids [20], insulin (Phadebas), and HDL cholesterol. The coefficients of variation of our methods were for total cholesterol $4.7 \%$, triglycerides $4.7 \%$, phospholipids $5.3 \%$, HDL cholesterol $3.6 \%$, and insulin $9.4 \%$. Insulin was determined after pretreatment of plasma with polyethyleneglycol in order to remove antibodies which may be present as a result of insulin treatment [21]. Ten minutes after glucose injection, insulin was again determined to assess the early insulin response. HDL cholesterol was determined after precipitation of VLDL and LDL by sodium phosphotungstate and magnesium chloride [22]. Glucose concentration was determined in whole blood by an automated hexokinase method.

For the determination of concentration and composition of the main lipoprotein density classes, namely VLDL, IDL (intermediate density lipoproteins), $\mathrm{LDL}, \mathrm{HDL}_{2}$, and $\mathrm{HDL}_{3}$, we used rate zonal ultracentrifugation [23]. The lipoprotein concentrations were calculated as the sum of total cholesterol, triglyceride, phospholipid, and protein [24] in each lipoprotein fraction. Because of dilution of lipoprotein fractions during separation by high salt concentrations, the ultracentrifugal fractions were concentrated by membrane pressure filtration (Collodion-Bags SM 13200 Sartorius-Membranfilter $\mathrm{GmbH}$, Göttingen) to about one fifteenth of their original volume, then diluted with water to plasma density, and finally concentrated again. Triglyceride concentration was thus determined in a 15 -fold concentrated sample.

Since many of the measured paramenters had a lognormal distribution (fasting blood glucose, $\mathrm{K}_{\mathrm{g}}$, plasma concentration of insulin, triglycerides, HDL cholesterol, VLDL, IDL, $\mathrm{HDL}_{2}, \mathrm{HDL}_{3}$ ), median and range of all parameters were indicated in the tables. Statistical calculations were performed using the non-parametric Wilcoxon test for comparison of unpaired measurements. Correlation analyses were performed by the method of the least squares. In the case of log-normally distributed variables, correlations were calculated out after logarithmic transformation of the data.

\section{Results}

Table 1 shows the clinical and biochemical characteristics of the 4 groups of patients. There were no significant differences between the groups with regard to duration of diabetes, sex, age, or relative body weight. Fasting blood glucose was lowest in the control group, slightly elevated in the diet-treated group, and highest in the insulin and sulphonylurea groups. Correspondingly, $\mathrm{K}_{\mathrm{g}}$ and early insulin response were low in the insulin and sulphonylurea treated groups. In spite of the fact that no significant differences of fasting blood glucose were found between the insulin and sulphonylurea groups, $\mathrm{K}_{\mathrm{g}}$ was significantly higher in the sulphonylurea group.

Table 2 shows the lipid and lipoprotein concentrations of the four groups. The cholesterol and phos-
COMPOSITION OF LIPOPROTEINS I
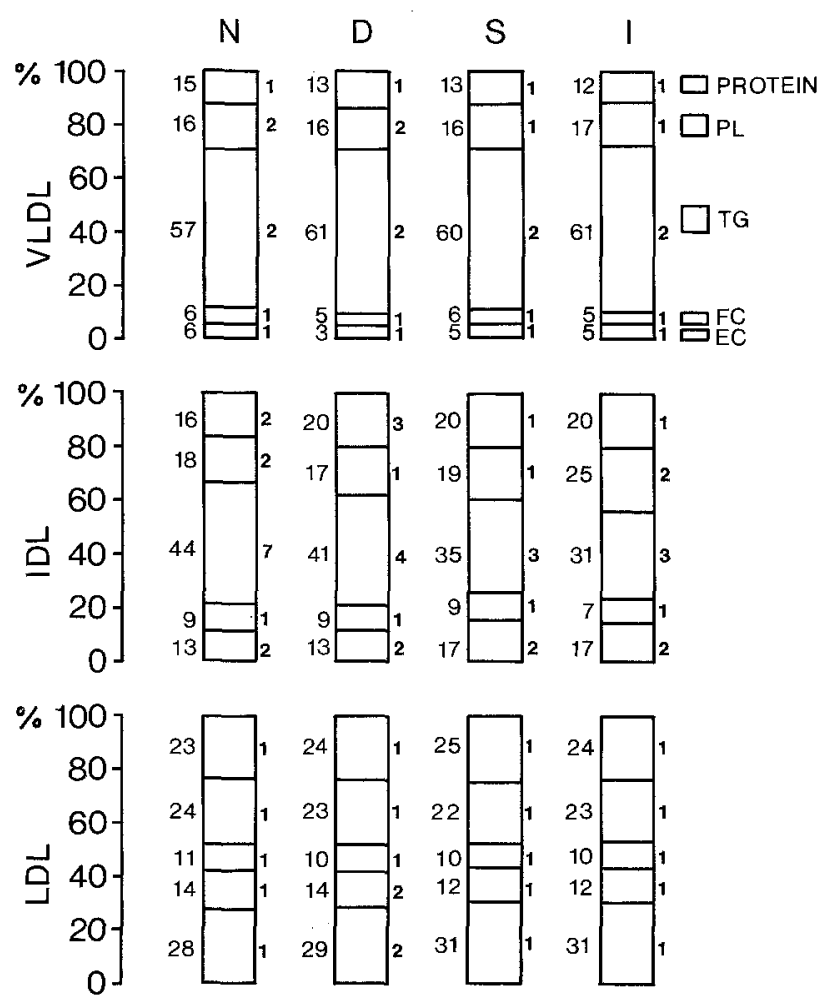

Fig. 1. Average percentage chemical composition of the lipoprotein fractions VLDL, IDL, and LDL of 12 normal individuals (N), 14 diet-treated diabetics (D), 32 sulphonylurea-treated diabetics (S), and 27 insulin-treated diabetics (I). EC: Esterified cholesterol; FC: Free cholesterol; TG: Triglycerides; PL: Phospholipids. The differences in the percentage content of protein, PL, TG, FC, and $\mathrm{EC}$ between the four groups of individuals were not significant for all three investigated lipoprotein fractions. The numbers on the left side of columns signify the mean values, whereas the SEM are indicated on the right side of the columns

pholipid concentrations did not differ significantly between the groups, whereas the plasma triglyceride concentration in the sulphonylurea group was significantly higher than in the control group. There were no striking differences of HDL cholesterol between control group, diet group, and insulin group. In contrast, there was a significant decrease of HDL cholesterol in the sulphonylurea group. Diabetics treated with sulphonylureas had, unlike the insulintreated group, significantly higher triglyceride, VLDL, and IDL levels and significantly lower LDL levels than the control group. A highly significant decrease of $\mathrm{HDL}_{2}$ was observed in the sulphonylurea group in comparison with the three other groups. There were no significant differences in $\mathrm{HDL}_{3}$ concentrations between the four groups. A direct comparison between the insulin and sulphonylurea groups revealed a significantly higher concentration of plasma triglycerides and significantly lower concen- 


\section{COMPOSITION OF LIPOPROTEINS II}

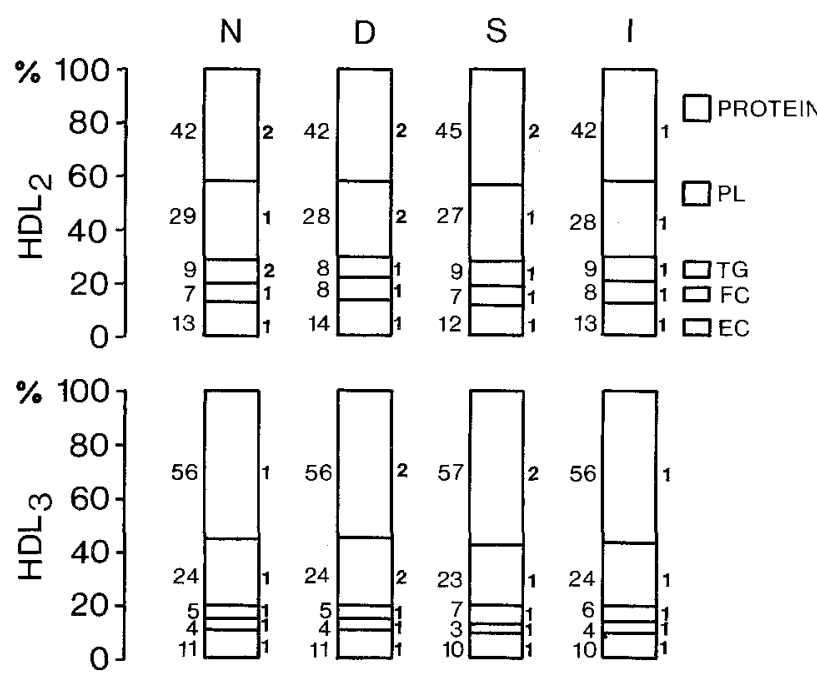

Fig. 2. Average percentage chemical compositon of the lipoprotein fractions $\mathrm{HDL}_{2}$ and $\mathrm{HDL}_{3}$ of 12 normal individuals, 14 diettreated diabetics, 32 sulphonylurea-treated diabetics, and 27 insulin-treated diabetics. The differences in the percentage content of protein, PL, TG, FC, and EC between the four groups of individuals were not significant for the two HOLL fractions. The numbers on the left side of the columns signify the mean values, whereas the SEM are indicated on the right side of the columns. For abbreviations see the legend to Figure 1

trations of $\mathrm{HDL}$ cholesterol and $\mathrm{HDL}_{2}$ in the sulphonylurea group.

There were no significant differences in the chemical composition of VLDL, IDL, LDL, $\mathrm{HDL}_{2}$, and $\mathrm{HDL}_{3}$ fractions between the control group and the three other diabetic groups.

If all studied individuals were analysed together, significant positive correlations were observed between the logarithm of fasting blood glucose on the one hand and the logarithm of plasma triglycerides $(\mathrm{r}=+0.28, \mathrm{p}<0.01)$ and the logarithm of plasma VLDL $(r=+0.23, p<0.05)$ on the other hand. The logarithm of blood glucose correlated negatively with the logarithm of plasma $\mathrm{HDL}_{2}$ concentration ( $\mathrm{r}=$ $-0.29, \mathrm{p}<0.01)$. Furthermore, the logarithm of plasma VLDL concentration could be correlated negatively with the logarithm of $\mathrm{HDL}_{2}(\mathrm{r}=-0.89$, $\mathrm{p}<0.001)$ and positively with the logarithm of IDL $(\mathrm{r}=+0.33, \mathrm{p}<0.01)$.

\section{Discussion}

The presented data demonstrate the well-known disturbance of lipid metabolism in patients with diabetes mellitus. The metabolic derangement was slight in patients who required only dietary treatment and more severe in insulin-treated and sulphonylureatreated individuals. As compared with a control group, however, no difference was found in lipid and lipoprotein metabolism in the diet-treated group or in the insulin-treated group. In contrast, the study revealed significant differences in the sulphonylurea group in comparison with the control group with regard to the plasma concentrations of triglycerides, VLDL, and IDL (higher) and the concentrations of $\mathrm{HDL}$ cholesterol, LDL, and $\mathrm{HDL}_{2}$ (lower). These data suggest impaired catabolism of triglyceride rich lipoproteins in tablet treated diabetics. It is known that lipoprotein lipase is under hormonal regulation by insulin $[25,26]$ and the activity of the enzyme in adipose tissue and muscle has been shown to be reduced in uncontrolled diabetes [27]. As there is a relationship between HDL cholesterol and lipoprotein lipase activity, both in post-heparin plasma and adipose tissue $[28,29]$, it is suggested that $\mathrm{HDL}_{2}$ are an end product of catabolism of triglyceride rich lipoproteins [30].

Because of the increases of triglyceride, VLDL, and IDL and the decrease of $\mathrm{HDL}_{2}$ concentration in the plasma of tablet treated diabetics as compared with the insulin-treated group, it appears that insulin, unlike sulphonylurea treatment, may at least partially overcome the defect in lipoprotein catabolism seen in diabetes. In view of the assumptions that HDL protect against atherosclerosis $[7,8]$, of the observation that $\mathrm{HDL}_{2}$ are lowered in patients with atherosclerosis [9], and of a negative association between vascular disease and HDL cholesterol in diabetics [15], it is possible that the atherogenic potential of diabetes mellitus may be reduced more effectively by insulin than by tablet treatment.

The correlation analyses on all our subjects favour the assumption that control of blood glucose has a key relationship to the regulation of lipoprotein homeostasis. Even though fasting blood glucose was nearly identical in the insulin and sulphonylurea groups, it can be assumed that the patients treated with long-acting insulin show better blood glucose values through the day. Further longitudinal studies on the effects of insulin and sulphonylureas on the lipoprotein pattern in diabetes mellitus are warranted to elucidate this problem.

Acknowledgements. We want to thank Ch. Comploy, M. HochStädele, and U. Egger-Büssing for their expert technical assistance.

\section{References}

1. Braunsteiner H, Sailer S, Sandhofer F, DiPauli R, Gabl F, Jung A (1965) Lipidwerte bei gesunden Personen und Patienten mit Myokardinfakt. Wien Klin Wochenschr 77: 859-862 
2. Kannel WB, McGee DL (1979) Diabetes and cardiovascular disease. The Framingham Study. JAMA 241: 2035-2038

3. New MI, Roberts TN, Bierman EL, Reader GG (1963) The significance of blood lipid alterations in diabetes mellitus. Diabetes 12: 208-212

4. Braunsteiner H, Sailer S, Sandhofer F (1966) Plasmalipide bei Patienten mit Diabetes mellitus. Klin Wochenschr 44: 116-119

5. Kaufmann RL, Assal JPH, Soeldner JS, Wilmshurst EG, Lemaire JR, Gleason RE, White B (1975) Plasma lipid levels in diabetic children. Effect of diet restricted in cholesterol and saturated fats. Diabetes 24: 672-679

6. Hayes TM (1972) Plasma lipoproteins in adult diabetes. Clin Endocrinol (Oxf) 1: 247-251

7. Miller GJ, Miller NE (1975) Plasma-high-density-lipoprotein concentration and development of ischaemic heart-disease. Lancet 1: 16-19

8. Castelli WP, Doyle JT, Gordon T, Hames CG, Hjortland MC, Hulley SB, Kagan A, Zukel WJ (1977) HDL cholesterol and other lipids in coronary heart disease. The cooperative lipoprotein phenotyping study. Circulation 55: 767-772

9. Gofman JW, Young W, Tandy R (1966) Ischaemic heart disease, atherosclerosis, and longevity. Circulation 34: 679-697

10. Lopes-Virella MFL, Stone PG, Colwell JA (1977) Serum high density lipoprotein in diabetic patients. Diabetologia 13: 285-291

11. Elkeles RS, Wu J, Hambley J (1978) Haemoglobin $\mathbf{A}_{1}$, blood glucose, and high-density lipoprotein cholesterol in insulinrequiring diabetics. Lancet II: 547-548

12. Calvert GD, Graham JJ, Mannik T, Wise PH, Yeates RA (1978) Effects of therapy on plasma-high-density-lipoproteincholesterol concentration in diabetes mellitus. Lancet II: 66-68

13. Paisey R, Elkeles RS, Hambley J, Magill P (1978) The effects of chlorpropamide and insulin on serum lipids, lipoproteins and fractional triglyceride removal. Diabetologia 15: 81-85

14. Kennedy AL, Lappin TRJ, Lavery TD, Hadden DR, Weaver JA, Montgomery DAD (1978) Relation of high-density lipoprotein cholesterol concentration to type of diabetes and its control Br Med J II: 1191-1194

15. Reckless JPD, Betteridge DJ, Wu P, Payne B, Galton DJ (1978) High-density and low-density lipoproteins and prevalence of vascular disease in diabetes mellitus. $\mathrm{Br}$ Med $\mathrm{J} \mathrm{I}$ : 883-886

16. Documenta Geigy (1968) Wissenschaftliche Tabellen, 7. Aufl. Ciba Geigy SA, Basel

17. Röschlau P, Bernt E, Gruber W (1974) Enzymatische Bestimmung des Gesamtcholesterins im Serum. J Clin Chem Clin Biochem 12: 403-407
18. Patsch W, Sailer S, Braunsteiner H (1976) An enzymatic method for the determination of the initial rate of cholesterol esterification in human plasma. J Lipid Res 17: 182-185

19. Kessler G, Lederer H (1966) In: Skeggs LT (ed) Automation in analytical chemistry. Technicon Symposion, p 341-344

20. Bartlett GR (1959) Phosphorus assay in column chromatography. J Biol Chem 234: 466-468

21. Nakagawa S, Nakayama H, Sasaki T, Yoshino K, Yu YY, Shinozaki K, Aoki S, Mashimo K (1973) A simple method for the determination of serum free insulin levels in insulintreated patients. Diabetes 22: 590-600

22. Burstein M, Scholnick HR, Morfin R (1970) Rapid method for the isolation of lipoproteins from human serum by precipitation with polyanions. J Lipid Res 11: 583-595

23. Patsch JR, Sailer S, Kostner G, Sandhofer F, Holasek A, Braunsteiner H (1974) Separation of the main lipoprotein density classes from human plasma by ratezonal ultracentrifugation. J Lipid Res 15: 356-366

24. Lowry $\mathrm{OH}$, Rosebrough NJ, Farr AL, Randall RJ (1951) Protein measurement with the Folin phenol reagent. J Biol Chem 193: 265-275

25. Borensztain J, Samols DR, Rubinstein AH (1972) Effects of insulin on lipoprotein lipase activity in the rat heart and adipose tissue. Am J Physiol 223: 1271-1275

26. Garfinkel AS, Nilsson-Ehle P, Schotz MC (1976) Regulation of lipoprotein lipase induction by insulin. Biochem Biophys Acta 424: 264-273

27. Taskinen M-R, Nikkilä EA (1979) Lipoprotein lipase activity of adipose tissue and skeletal muscle in insulin-deficient human diabetes. Diabetologia 17: 351-356

28. Nikkilä EA, Hormila $P(1978)$ Serum lipids and lipoproteins in insulin-treated diabetes. Diabetes 27: 1078-1086

29. Nikkilä EA, Taskinen M-R, Kekki M (1978) Relation of plasma high density lipoprotein cholesterol to lipoprotein lipase activity and skeletal muscle tissues of man. Atherosclerosis 29: 497-501

30. Patsch JR, Gotto AM, Olivecrona T, Eisenberg S (1978) Formation of high density lipoprotein ${ }_{2}$-like particles during lipolysis of very low density lipoproteins in vitro. Proc Natl Acad Sci USA 75: 4519-4523

Received: February 6, 1980,

and in revised form: October 8,1980

Dr. Hans-Jörg Lisch

Universitätsklinik für Innere Medizin

Anichstraße 35

A-6020 Innsbruck

Austria 